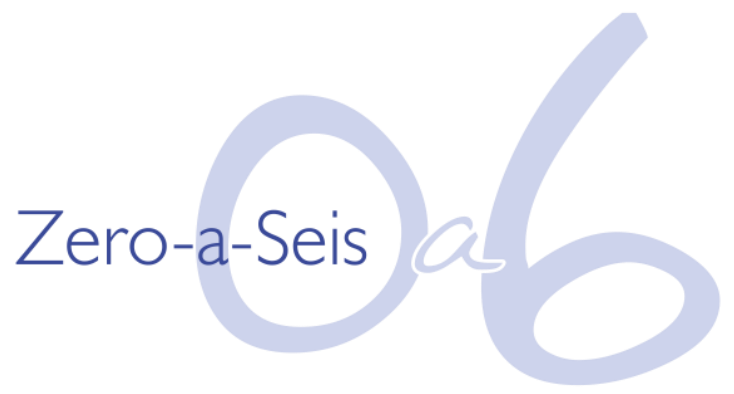

\title{
CAMINHOS DA PARTICIPAÇÃO SOCIAL NA FORMULAÇÃO DE POLÍTICAS PÚBLICAS: INFÂNCIA E MIGRAÇÃO INTERNACIONAL EM SÃO PAULO
} Social participation pathways on the formulation of public policies: childhood and international migration in São Paulo

\author{
Tatiana Chang WALDMAN \\ Faculdade de Direito \\ Universidade de São Paulo (FD-USP) \\ São Paulo, Brasil \\ tatiana.waldman@gmail.com \\ https://orcid.org/0000-0002-4517-7833
}

\author{
Camila Barrero BREITENVIESER \\ Fundação Getúlio Vargas (FGV-EAESP) \\ São Paulo, Brasil \\ camilabreitenvieser@gmail.com \\ https://orcid.org/0000-0002-0983-404X (D)
}

A lista completa com informações dos autores está no final do artigo

\section{RESUMO}

Este artigo propõe apresentar reflexões sobre a inclusão da infância nas duas Conferências Municipais de Políticas para Imigrantes realizadas em São Paulo. Analisar a forma como o tema foi abordado nesse espaço de participação social se mostra relevante já que nele são debatidas as principais demandas da e pela população migrante e são elencadas as prioridades que servem de subsídio para atuação do governo local. A análise é feita a partir da observação de pontos centrais: os eixos temáticos nos quais as discussões foram organizadas, as propostas elaboradas e aprovadas, o número de crianças presentes nas conferências e a forma como foi pensada a sua participação. A principal metodologia utilizada é a análise documental, tendo sido selecionados documentos oficiais. Conclui-se que o tema ganhou relevância de uma edição para outra e que a inclusão da criança de forma participativa apresenta grande potencialidade para o enriquecimento do debate sobre a formulação de políticas públicas.

PALAVRAS-CHAVE: Infância. Participação social. Migração internacional. São Paulo.

\begin{abstract}
This article intends to present considerations about the inclusion of childhood in the two Municipal Immigration Policy Conferences held in São Paulo. It is relevant to analyze how the theme was approached in this social participation environment since it is where the migrant population discusses their main demands and it is where the priorities that are listed by them aim to be an input for the performance of the local government. The analysis is made by observing four main points: the guiding axes that organized the debate by themes, the drawn up and approved proposals, the quantity of children present at the conferences and the way how their participation was conceived. The key methodology employed is the documentary analysis by selecting and reviewing the official documents. The research concludes that the theme achieved more relevance from one edition to the other, and that the inclusion of children in a participatory way has a great potential for improving the debate on the formulation of public policies.

KEYWORDS: Childhood. Social participation. International migration. São Paulo.
\end{abstract}




\section{INTRODUÇÃO}

A mobilidade humana é um tema cada vez mais presente na agenda de diferentes países. Diante do incremento e da diversificação dos movimentos migratórios, a sociedade global e os Estados nacionais têm sido convocados a refletir sobre diferentes assuntos relacionados à migração, a fim de melhor compreendê-la, e sobre como implementar respostas adequadas às especificidades dos grupos populacionais que compõem tais mobilidades.

Dentre as pessoas que se movimentam pelo mundo estão muitas crianças e jovens que ainda não completaram 18 anos de idade ${ }^{1}$. Há aquelas que migram acompanhadas de suas famílias e outras que realizam o processo migratório sem a presença das mesmas ${ }^{2}$. Em meio a estas últimas, há crianças migrantes desacompanhadas, conceito que inclui todas aquelas que migram sem 0 acompanhamento de um adulto responsável por seu cuidado com base em lei ou costume do país que as recebe. E ainda, há crianças migrantes separadas que são aquelas que estão acompanhados de algum adulto, mas que migram sem a mãe e o pai ou outro adulto responsável legal ou costumeiro, embora não necessariamente sem a presença de outros familiares (OIM, 2018).

Há inclusive crianças e jovens que chegam aos países de destino sem documentos de identificação comprobatórios de sua idade pelos mais diversos motivos, dentre eles a origem rural e o pertencimento a um grupo social minoritário (KOZICA; VAN ELK, 2020).

Em termos quantitativos, em 2018, uma em cada oito pessoas na condição de migrantes internacionais eram crianças ou jovens com menos de 18 anos de idade (UNICEF, 2020), cabendo indicar que a população migrante internacional era então formada por aproximadamente 272 milhões de pessoas (ONU, 2019). E também que crianças ou jovens correspondiam a cerca de metade da população de pessoas em situação de refúgio, constituída por 25,9 milhões de refugiados e 3,5 milhões de solicitantes de refúgio (UNHCR, 2019).

\footnotetext{
${ }^{1}$ A Convenção sobre os Direitos da Criança (ONU, 1989), promulgada no Brasil por meio do Decreto no 99.710 de 21 de novembro de 1990, considera como criança "todo ser humano com menos de dezoito anos de idade". Para este artigo, no entanto, será adotado o conceito de criança como a pessoa de até doze anos de idade incompletos e adolescente como pessoa entre doze e dezoito anos de idade, de acordo com o estabelecido Estatuto da Criança e do Adolescente (ECA), Lei no 8.069 de 13 de julho de 1990.

2 Cabe mencionar que a reunião com mães e pais migrantes pode ser uma das possíveis razões da mobilidade de crianças.
} 
No mesmo período, crianças ou jovens com menos de 18 anos de idade representavam $30 \%$ das vítimas de tráfico de pessoas no mundo ( $23 \%$ do sexo feminino e $7 \%$ do sexo masculino). Na América do Sul, as porcentagens são mais altas e indicavam que $37 \%$ das vítimas pertenciam a essa faixa etária, $31 \%$ do sexo feminino e 6\% do sexo masculino (UNODC, 2018) ${ }^{3}$.

A significativa presença desse grupo populacional nas migrações internacionais torna imprescindível a adoção de um olhar especialmente atento à questão das crianças e jovens migrantes, tendo em vista a sua necessária proteção e a construção de políticas públicas que garantam o exercício de seus direitos fundamentais a partir de suas especificidades.

Ao mesmo tempo em que a idade é uma causa de vulnerabilidade 4 e que, portanto, todas as pessoas com menos de 18 anos devem ser destinatárias de uma especial assistência e cuidados em consideração a incipiente maturidade, a dependência e as necessidades de desenvolvimento (KOZICA; VAN ELK, 2020), não se pode deixar em um segundo plano a agência dessa população, seu conhecimento, suas experiências e as necessidades que transcendem a sua existência atrelada estritamente ao campo das relações parentais ou familiares.

É determinante entender a complexidade do papel das crianças e jovens inseridas em movimentos migratórios familiares. Em muitas situações elas são apresentadas como a principal razão da migração, motivada pelas oportunidades de um futuro melhor para as gerações mais jovens. Contudo, não é a regra que elas sejam consultadas sobre a decisão de migrar e muitas vezes são apenas informadas. E mesmo nas situações em que são consultadas e que haja um diálogo, dificilmente poderão dimensionar as implicações da mobilidade (CLACSO, 2020).

Fato é que as experiências ao longo do processo, que incluem desde a viagem até a chegada e o estabelecimento no país de destino, são muito distintas das vivenciadas pelos adultos. No entanto, ainda é incipiente o interesse analítico pela vivência de crianças e jovens como sujeitos migrantes, sendo mais frequente o foco

\footnotetext{
${ }^{3} \mathrm{~A}$ atenção à faixa etária e ao gênero das vítimas se reflete nas discussões sobre o tráfico de pessoas e no próprio Protocolo de Palermo, intitulado "Protocolo Adicional à Convenção das Nações Unidas contra o Crime Organizado Transnacional relativo à Prevenção, Repressão e Punição do Tráfico de Pessoas, em Especial de Mulheres e Crianças".

${ }^{4} \mathrm{O}$ conceito de condição de vulnerabilidade inclui pessoas que enfrentam especiais dificuldades em exercer de forma plena, perante o sistema de justiça, os seus direitos, em razão de idade, gênero, estado físico ou mental, circunstâncias sociais, econômicas, étnicas e/ou culturais, entre outras. Conferir especialmente a regra 5 das Regras de Brasília Sobre Acesso à Justiça das Pessoas em Condição de Vulnerabilidade (Conferência Judicial Ibero-Americana, 2008).
} 
dessa população enquanto parte de um binômio aparentemente indissociável com suas mães, seus pais ou responsáveis legais (CLACSO, 2020).

Em âmbito regional, a questão tem merecido especial atenção. Cabe mencionar alguns marcos. Um deles é o Parecer Consultivo OC-21/14 "Direitos e Garantias de crianças no contexto da migração e/ou necessidade de proteção internacional", enunciado pela Corte Interamericana de Direitos Humanos em resposta a solicitação apresentada em 2011 por Argentina, Brasil, Paraguai e Uruguai que adotaram um consenso prévio sobre a matéria. Importa ressaltar que uma decisão da Corte Interamericana tem peso significativo no estabelecimento de um piso mínimo de obrigações dos Estados de origem, trânsito e destino para assegurar a proteção dos direitos das crianças migrantes (IPPDH, 2015).

Outro marco regional é o lançamento, desde 2018, do Diálogo Regional Foco Infância Migrante pelo Instituto de Políticas Públicas em Direitos Humanos do MERCOSUL com uma série de atividades e eventos com o fim de articular ações, identificar boas práticas e elaborar propostas orientadas em resposta a violação de direitos de crianças migrantes por meio de uma abordagem regional (IPPDH, 2019).

Particularmente no Brasil, o tema tem se mostrado cada vez mais em pauta. Entre junho de 2019 e janeiro de 2020, por exemplo, uma iniciativa financiada pela União Europeia e executada pelo Centro Internacional para o Desenvolvimento de Políticas Migratórias se deu com a proposta de auxiliar o Governo Brasileiro, sobretudo a Defensoria Pública da União, a partir da troca de conhecimentos entre pares para trabalhar com crianças e adolescentes migrantes, especialmente a situação das estabelecidas nos estados de Roraima e Amazonas, estados com expressivos movimentos migratórios provenientes da Venezuela (KOZICA; VAN ELK, 2020).

Tratando mais uma vez da acolhida de pessoas de origem venezuelana, outro estudo foi publicado em 2020, desta vez pelo Consejo Latinoamericano de Ciencias Sociales (CLACSO, 2020), sobre crianças e jovens migrantes venezuelanos no Brasil, Colômbia, Equador e Peru. Mencionando dados do Relatório do Fundo das Nações Unidas para a Infância (2019), é apresentada a significativa presença de crianças e jovens no movimento de pessoas venezuelanas e seu impacto na dinâmica migratória regional: são aproximadamente 1,1 milhão de crianças e jovens venezuelanos que migram com sua família ou sozinhos. No Brasil, chegam a representar quase $50 \%$ do movimento de pessoas originárias da Venezuela para o território brasileiro.

Observa-se que hoje no Brasil o tema tem se destacado especialmente vinculado à chegada de crianças e adolescentes venezuelanos nos estados de Roraima e 
Amazonas. Entretanto, outros estados também têm refletido e trabalhado sobre o tema mesmo antes deste período. Em São Paulo, a preocupação com a infância e juventude migrante foi registrada na Política Municipal para a População Imigrante ${ }^{5}$ estabelecida a partir de 2016 e tem sido discutida, ainda que de forma tímida, em diálogos para a construção de políticas públicas direcionadas aos migrantes residentes na cidade. Tal preocupação transparece também em ações adotadas pelo município, como por exemplo, a estruturação de um Centro de Acolhida emergencial em 2015, para receber mães e crianças oriundas sobretudo de Angola.

Nesse sentido, a proposta deste artigo é apresentar reflexões sobre o tema da infância migrante - de pessoas migrantes de até doze anos de idade incompletos - a partir do contexto da cidade de São Paulo e das duas Conferências Municipais de Políticas para Imigrantes realizadas nos anos de 2013 e 2019 . O objetivo é analisar como o tema da infância apareceu nas duas conferências - nos eixos temáticos definidos, nas propostas elaboradas e aprovadas, no número de crianças presentes e na forma como se deu a sua participação nas conferências.

A opção por analisar o município de São Paulo foi motivada pelo fato do mesmo acolher uma população aproximada de 361 mil migrantes de diferentes nacionalidades e pela criação inédita no país de um órgão - a Coordenação de Políticas para Imigrantes e Promoção do Trabalho Decente (CPMigTD) - responsável pela implementação de políticas locais destinadas a essa população e de mecanismos de participação ativa de migrantes na tomada de decisões, tendo como marco as Conferências Municipais de Políticas para Imigrantes (SMDHC, no prelo).

As mencionadas conferências assumem o papel de promover a participação social e política de migrantes, além de se constituírem como espaços de diálogo e aprofundamento de debates entre a população e a gestão pública municipal. Nelas são definidos pela população temas prioritários e as diretrizes que servem de subsídio para a construção de políticas públicas locais. Por essa razão, observar a forma como surge a temática da criança nas duas conferências já realizadas torna possível compreender se a questão da infância foi discutida e registrada como uma demanda prioritária sob o olhar da própria população migrante de distintas nacionalidades e regiões da cidade.

\footnotetext{
${ }^{5} \mathrm{O}$ município de São Paulo adota o conceito de população imigrante para "todas as pessoas que se transferem de seu lugar de residência habitual em outro país para o Brasil, compreendendo imigrantes laborais, estudantes, pessoas em situação de refúgio, apátridas, bem como suas famílias, independentemente de sua situação imigratória e documental" (artigo 10, parágrafo único, Lei n. ${ }^{\circ} 16.478$, de 8 de julho de 2016, documento legal que institui a Política Municipal para a População Imigrante).
} 
Em vista de alcançar o objetivo descrito, foram analisados os quatro pontos mencionados acima: eixos temáticos, propostas apresentadas, número de crianças presentes e forma de participação das mesmas. A metodologia central utilizada foi a análise documental. No caso da primeira edição, foi analisado o Documento Final da $1^{a}$ Conferência Municipal de Políticas para Imigrantes (2013), documento síntese que contém as propostas finais aprovadas e informações relativas às propostas iniciais elaboradas. Para a segunda edição, foram analisados os documentos disponíveis no site da Secretaria Municipal de Direitos Humanos e Cidadania, tais como: atas das reuniões do Conselho Municipal de Imigrantes (CMI) e da Comissão Organizadora da Conferência (COM), Resoluções do CMI relativas à Conferência, Caderno da Conferência (2019), Propostas Aprovadas na Plenária Final, Documento de Metodologia, Documento de Codificação de Propostas (iniciais), e ainda o Relatório Final (no prelo). Além disso, foram enviadas perguntas, via sistema e-Sic (Lei de Acesso à Informação), para algumas secretarias municipais que buscaram mapear as ações com foco na criança migrante realizadas pelas mesmas. Finalmente, cabe observar que as autoras deste artigo estiveram presentes em todas as etapas de realização da $2^{a}$ Conferência.

\section{A POLÍtTICA MUNICIPAL PARA POPULAÇÃO IMIGRANTE E A INFÂNCIA}

Comumente, as migrações internacionais são tratadas em termos de estabelecimento de regras de entrada e permanência de pessoas em um determinado território nacional ${ }^{6}$, predominando o aspecto do controle migratório.

No Brasil, a política migratória é estabelecida especialmente na esfera federal ${ }^{7}$ e muito embora tenha havido uma mudança na legislação migratória nacional, pautada especialmente na garantia de direitos humanos, essa característica do controle migratório permanece. E, ainda que haja a menção da construção de uma Política Nacional de Migrações, Refúgio e Apatridia de forma coordenada e articulada entre políticas setoriais e unidades federativas ${ }^{8}$, não houve, até o momento, avanços

\footnotetext{
${ }^{6}$ As políticas migratórias, nesse aspecto, podem ser definidas como as leis e as regulamentações que os Estados desenham e implementam com o objetivo de alterar o volume, as origens e a composição dos fluxos migratórios (CZAIKA; DE HAAS, 2011).

7 A Constituição Federal vigente estabelece em seu artigo 22 que é da União a competência de legislar sobre "nacionalidade, cidadania e naturalização" (inciso XIII) e sobre "emigração e imigração, entrada, extradição e expulsão de estrangeiros" (inciso XV), cunhando um arranjo institucional da gestão da migração na esfera federal.

8 O artigo 120 da Lei Federal 13.445 de 2017 prevê: "a Política Nacional de Migrações, Refúgio e Apatridia terá a finalidade de coordenar e articular ações setoriais implementadas pelo Poder Executivo federal em regime de cooperação com os Estados, o Distrito Federal e os Municípios, com participação de organizações da sociedade civil, organismos internacionais e entidades privadas, conforme regulamento".
} 
significativos no sentido de efetivar a construção de uma política sólida em relação às capacidades e competências dos entes federados. A permanência da ausência de determinações legais claras aos entes subnacionais acaba por gerar alta discricionariedade no que tange à implementação de políticas locais de acolhimento e integração de migrantes.

A Prefeitura de São Paulo tem sido referência no endereçamento local de políticas para migrantes tanto em âmbito nacional como internacional. Em 2013 é criado um órgão transversal destinado à promoção de políticas públicas nas quais a população migrante é o público-alvo central. A partir de então, a política pública estruturada na cidade diferencia-se das iniciativas anteriormente realizadas por dois motivos principais: pela compreensão do migrante como segmento social, com demandas específicas e multidimensionais; e, pela promoção da cidadania local e de respostas integrais, motivadas, em parte expressiva dos casos, pelo arranjo de coordenação orientado para a articulação entre diversas secretarias municipais e suas políticas setoriais (BREITENVIESER, 2019).

Em 2016 é aprovada a Lei Municipal no 16.478/2016, que institui a Política Municipal para a População Imigrante e atribui responsabilidades às respectivas secretarias municipais. Dentre as diretrizes estabelecidas pela lei, encontra-se a priorização de direitos e o bem-estar da criança e do adolescente migrantes, e dentre as ações prioritárias está a garantia de que todas as crianças e adolescentes (além de pessoas adultas) migrantes tenham direito à educação na rede de ensino público municipal, por meio do seu acesso, permanência e terminalidade.

Ainda no que tange à infância algumas iniciativas levadas a cabo pelo município podem ser evidenciadas.

Segundo dados da Secretaria Municipal de Educação (SME), em 2016, os migrantes representavam $0,45 \%$ dos alunos da rede municipal de ensino e eram provenientes de 73 países diferentes (VENTURA; GUIMARÃES; REIS, 2017). A maior parte das matrículas de migrantes na educação municipal se concentrava nas préescolas ( $25 \%$ do total de matrículas de migrantes) e no Ensino Fundamental I (37\%), e um pouco menos expressiva no Ensino Fundamental II (20\%) (VENTURA; GUIMARÃES; REIS, 2017). Incluídas as crianças migrantes matriculadas em creches (cerca de $10 \%)$, é possível sugerir que a maior parte $(72 \%)$ dos alunos migrantes matriculados no sistema público e municipal de ensino em 2016 tinham até 10 anos de idade. 
A temática migratória na SME é debatida dentro do Núcleo de Educação ÉtnicoRacial, cujas principais ações são o assessoramento na formulação de currículos, a formação de seus servidores com foco nas populações negra, afrodescendente, indígena e imigrante, e a organização de eventos culturais nas três linhas de trabalho desenvolvidas: Educação Intercultural; Imigração como Direito Humano; e Combate à Discriminação, Racismo, Preconceito e Xenofobia. Desde 2014, o Núcleo promove bianualmente a "Mostra Cultural Dezembro Imigrante", onde são feitas atividades relacionadas ao tema.

Relativamente à assistência social e infância, no site da Secretaria Municipal de Assistência e Desenvolvimento Social (SMADS) é possível acessar a base de dados do Sistema de Informação do Atendimento aos Usuários (SISA) que disponibiliza informações de cadastro e prontuário unificados para todos os usuários da rede socioassistencial conveniada. A consulta à base de dados permitiu apurar que 200 crianças migrantes nascidas entre 2007 e 2019 eram usuárias dos serviços socioassistenciais oferecidos e registrados no sistema em $2019^{9}$.

Dentre os serviços sociais procurados por migrantes estão o acesso à creche (de incumbência municipal) e atividades do contra-turno escolar (VENTURA; GUIMARÃES; REIS, 2017). Na estrutura organizativa da SMADS há uma Coordenação de Proteção Social Básica que oferece alguns serviços destinados a crianças e adolescentes que visam à ampliação da sociabilidade e prevenção de situações de risco pessoal e social, como é o caso dos Centros para Crianças e Adolescentes, do Clube da Turma, do Circo Social e do Centro de Convivência Intergeracional. No entanto, a SMADS não coleta a informação da nacionalidade dos atendidos em nenhum dos programas citados ${ }^{10}$.

Uma ação coordenada entre a SMADS e a CPMigTD merece destaque, tendo ocorrido em 2015 quando chegaram a cidade um número expressivo de mulheres angolanas $^{11}$ grávidas, muitas vezes acompanhadas de crianças e sem os pais. $A$ particularidade do fluxo migratório em questão levou o município a estruturar um equipamento emergencial de acolhida adequado às necessidades desse perfil populacional e que posteriormente se tornou permanente (SAMPAIO; BARALDI, 2019).

\footnotetext{
9 Serviços que apresentaram crianças migrantes como usuárias no ano de 2019: Centros de Acolhida, Centro Temporário de Acolhimento, Autonomia em Foco, Família em Foco, Serviço de Acolhimento institucional para Crianças e Adolescentes.

${ }^{10}$ Informação obtida por meio da Lei de Acesso a Informação, conforme protocolo no 46821 de 2020.

${ }^{11} \mathrm{Em} 2016$ os atendimentos feitos pela SMADS a mulheres e crianças, 42,5\% eram de mulheres angolanas que foram cadastradas no SISA (VENTURA; GUIMARÃES; REIS, 2017).
} 


\section{AS CONFERÊNCIAS MUNICIPAIS DE POLÍTICAS PARA IMIGRANTES}

No contexto da construção da política municipal para migrantes está a valorização da participação social. A lei municipal que versa sobre essa política prevê a criação do Conselho Municipal de Imigrantes e o estabelecimento do diálogo permanente entre o poder público e a sociedade civil, em especial por meio de audiências, consultas públicas e conferências.

Nesse rol de ações se insere a realização de duas Conferências Municipais de Políticas para Imigrantes: a primeira em 2013 e a segunda em 2019.

A primeira conferência municipal teve como lema "Somos Tod@s Migrantes" e despontava como um processo participativo de migrantes inédito não somente no município de São Paulo, mas em todo o Brasil. Esta foi convocada com o objetivo de aprofundar o debate e elaborar propostas e diretrizes direcionadas para os três níveis federativos (municipal, estadual e federal). Além de servir como subsídio para a construção de políticas locais, a conferência municipal também cumpriu o papel de etapa preparatória para a realização da Conferência Nacional sobre Migrações e Refúgio, elegendo delegados que representariam a cidade na etapa nacional (SMDHC, 2013).

Todo o processo foi planejado e executado pela Comissão Organizadora, composta paritariamente por 28 representantes do governo municipal e organizações da sociedade civil. As organizações da sociedade civil foram indicadas por duas redes de organizações: o Fórum Social pelos Direitos Humanos e Integração dos Imigrantes no Brasil e a REDE Interinstitucional em Prol do Imigrante (SMDHC, 2013).

Já a segunda Conferência Municipal de Políticas para Imigrantes, realizada em 2019, teve como lema "Somos Tod@s Cidadãos". Dentre os objetivos dessa edição estavam, especialmente, o aprofundamento do debate sobre a migração e a promoção da participação social e política de migrantes, a elaboração de propostas e diretrizes dessa vez exclusivamente para o nível federativo local ${ }^{12}$ - que fundamentassem as políticas públicas para essa população e a proposição de bases para a criação de um Plano Municipal.

Uma vez que o Conselho Municipal de Imigrantes já havia sido constituído, a competência de convocação e realização das conferências passou a ser desse órgão colegiado, tendo previsão de realização de uma edição a cada dois anos. O CMI definiu

\footnotetext{
12 Não houve ligação com outras etapas, uma vez que apenas o nível municipal organizou uma segunda edição desse tipo de conferência. Não há, até o momento, indicativo de mobilização em outros níveis.
} 
os objetivos da segunda conferência e convocou a Comissão Organizadora de modo a ampliar a participação da sociedade civil no decorrer do processo.

Ambas as edições foram antecedidas por etapas preparatórias que tinham como objetivo a elaboração de propostas que seriam sistematizadas e encaminhadas para discussão ao longo das conferências. Duas modalidades de realização ${ }^{13}$ das etapas preparatórias foram verificadas: os encontros convocados pela Comissão Organizadora (chamadas de Etapas Mobilizadoras na primeira edição e de Pré-conferências segunda edição) e os encontros organizados por entidades da sociedade civil (nomeados como Etapas Livres na primeira edição e Conferências Livres na segunda edição).

A primeira edição contou com quatro encontros realizados pela Comissão Organizadora e nove encontros convocados por entidades da sociedade civil, resultando na formulação de 463 propostas. Já a segunda edição contou com quatro encontros realizados pela Comissão Organizadora e dezoito encontros convocados por entidades da sociedade civil, resultando em 482 propostas.

Durante o intervalo entre as duas edições - entre os anos de 2013 e 2019 - é possível observar o aprofundamento da política pública voltada a essa população implementada na cidade, assim como diferenças significativas no campo migratório nacional e local - como a aprovação de uma nova Lei de Migração em 2017 e da Política Municipal para População Imigrante em 2016 ou mesmo a intensificação e diversificação de movimentos migratórios como os originários do Haiti e da Venezuela para o Brasil.

Um ponto de mudança que merece ser destacado é a ampliação e o fortalecimento de organizações da sociedade civil que atuam na temática na cidade de São Paulo ao longo desse intervalo. São, sobretudo, novas organizações, coletivos, grupos ou associações protagonizadas por imigrantes que estruturaram suas próprias ações e reivindicam a garantia de seus direitos (SMDHC, no prelo).

A expansão de atores pode ser observada no acréscimo do número de integrantes das duas comissões organizadoras. Em 2013, era formada por 28 representantes e em 2019, passa a contar com 47 representantes ${ }^{14}$. Ou ainda no incremento do número de

\footnotetext{
13 Na conferência de 2019 uma terceira modalidade de participação da etapa preparatória foi prevista: o envio de propostas individuais online, que poderiam ser submetidas por imigrantes exclusivamente e independentemente da nacionalidade e da situação migratória ou documental. No entanto, não foi registrada nenhuma proposta nessa modalidade (SMDHC, 2019a).

${ }_{14}$ A Comissão Organizadora foi formada inicialmente por 35 membros (15 representantes do poder público; 15 representantes da sociedade civil e 5 convidados), conforme a Resolução no 01/CMI/2019. Tendo diagnosticado a necessidade de ampliação da COM, o CMI abriu um prazo para que as organizações interessadas indicassem seus representantes. Uma nova resolução formalizou o alargamento da COM, que passou a contar com 47 membros, aumentando para 17 o número de organizações convidadas (Resolução no03/CMI/2019).
} 
encontros convocados por entidades da sociedade civil entre uma edição e outra (nove em 2013 e dezoito em 2019).

O aumento e a diversificação de atores na segunda edição foram acompanhados da reivindicação por maior protagonismo e participação nos processos decisórios e refletiram na ampliação e inclusão de novas pautas nos debates, como indica, por exemplo, a ampliação de tópicos abordados pelos eixos temáticos (quatro eixos na primeira edição e oito na segunda, como se discutirá a seguir). Nota-se, portanto, a relação entre a ampliação de atores e a abertura de espaço para a negociação sobre temáticas consideradas relevantes e sobre as definições utilizadas para compreensão a respeito de determinado problema público (BAUMGARTNER; JONES, 2009).

Sob esse espectro insere-se a temática da infância no contexto das migrações internacionais nas discussões e propostas aprovadas nas conferências municipais e sua priorização como demanda da população migrante no espaço de participação em questão.

\section{A INFÂNCIA NAS CONFERÊNCIAS MUNICIPAIS}

A análise da inclusão da infância migrante nas conferências municipais foi feita a partir da observação de pontos centrais, tais como os eixos temáticos nos quais se organizaram os debates, as propostas elaboradas nas etapas preparatórias e as posteriormente aprovadas nas plenárias finais, o número de crianças presentes nas diversas etapas das duas conferências, e a forma como foi pensada a sua participação ao longo das mesmas.

\section{Eixos temáticos}

Os eixos temáticos cumpriram a função de organizar a forma como os debates ocorreriam. Os organizadores de cada uma das edições selecionaram temas considerados prioritários a partir dos quais os participantes das conferências poderiam eleger os assuntos sobre os quais se ateriam detidamente para elaboração e seleção de propostas a serem enviadas para avaliação nas plenárias finais.

A primeira conferência foi estruturada a partir de quatro eixos temáticos: promoção e garantia de acesso a direitos sociais e serviços públicos; promoção do trabalho decente; inclusão social e reconhecimento cultural; e legislação federal e política nacional para as migrações e refúgio. No Documento Final dessa edição, as 
propostas aprovadas foram classificadas de acordo com os seguintes assuntos: assistência social; regularização/ desburocratização; saúde; acesso à educação, reconhecimento de diplomas, ensino da Língua Portuguesa; acesso e garantia ao trabalho decente, combate ao trabalho escravo; acesso e incentivo à cultura, reconhecimento e valorização da diversidade; legislação migratória nacional; acesso à informação e orientação, mapeamento e produção de dados; direitos políticos; campanha de conscientização e combate à xenofobia; política para as mulheres; participação social de imigrantes; e refúgio.

Constata-se que não há menção explicita à criança seja na definição dos eixos de trabalho, seja na categorização proposta pelo documento que apresenta o resultado final da conferência. O que sugere que, nesse momento, o tema da infância não era observado pela Coordenação, pela Comissão Organizadora ou pelos participantes da conferência como um tema prioritário a ponto de merecer destaque na forma de eixo temático ou de sistematização temática de propostas.

Em 2019, a segunda conferência foi estruturada em oito eixos de trabalho: participação social e protagonismo imigrante na governança imigratória local; acesso à assistência social e habitação; valorização e incentivo à diversidade cultural; proteção aos direitos humanos e combate à xenofobia, racismo, intolerância religiosa, e outras formas de discriminação; mulheres e população LGBTI+: acesso a direitos e serviços; promoção do trabalho decente, geração de emprego e renda e qualificação profissional; acesso à educação integral, ensino de língua portuguesa para imigrantes e respeito à interculturalidade; e acesso à saúde integral, lazer e esporte.

Mesmo havendo a ampliação de temas selecionados como prioritários para a estruturação dos eixos temáticos das conferências, nenhuma das duas edições dedicou um eixo específico para o tema da infância, ou mais amplamente da criança e do adolescente.

No entanto, a segunda conferência previu além dos eixos temáticos quatro temas transversais a serem observados. Dentre eles, um trazia a referência à especificidade da criança e do adolescente migrante junto a outros grupos e convidava os participantes a dedicarem especial atenção durante a elaboração e priorização de propostas:

(iii) zelar pela atenção específica às populações de: mulheres, LGBTI+, crianças e adolescentes, pessoas em privação de liberdade e egressas, pessoas idosas, em situação de rua, vítimas de trabalho escravo contemporâneo e tráfico de pessoas e pessoas em outras situações de vulnerabilidade social (SMDHC, 2019a, p. 12). 
Ressalta-se que embora o tema tenha sido tratado de forma transversal e associado a outros grupos populacionais, durante o processo avaliativo sobre a realização da segunda conferência, levado a cabo na 25a Reunião Ordinária do Conselho Municipal de Imigrante na qual estavam presentes membros da Comissão Organizadora, houve a sugestão de inclusão para a próxima conferência, a ser realizada em 2021, de um eixo específico com o tema das crianças e adolescentes migrantes. Este foi o único tema para o qual se sugeriu um eixo temático específico, o que indica a ampliação do destaque da temática de uma edição para outra (SMDHC, no prelo).

\section{PROPOSTAS ELABORADAS E APROVADAS}

Para análise dos dados relativos às propostas foram utilizados dois recortes. 0 primeiro se refere a elaboração de propostas iniciais nas etapas preparatórias - que são posteriormente sistematizadas e discutidas nos dias das conferências - e o segundo é relativo às propostas aprovadas nas plenárias finais de ambas as conferências.

No que diz respeito às propostas iniciais elaboradas na primeira conferência, a informação disponível no Documento Final (2013) indica que houve apenas uma proposta classificada com o tema "criança e adolescente".

Apesar da classificação sugerida pelo referido documento, uma análise mais profunda dos conteúdos das propostas finais indicou que mais de uma proposta tratou da matéria. Essa observação leva a supor duas possibilidades, não excludentes entre si: ou a classificação proposta pelo documento relaciona apenas a proposta que versou exclusivamente sobre o assunto, ou nos dias da conferência surgiram novas propostas sobre o tema.

Para análise das propostas iniciais da segunda conferência municipal foram selecionadas as propostas que continham expressamente as palavras-chave "criança"; "crianças"; "filho/s"; "filha/s". Foram encontradas 26 propostas, totalizando 6\% do total de propostas iniciais existentes (462).

Ainda sobre a elaboração de propostas iniciais, durante as etapas preparatórias da segunda conferência foi realizada uma conferência livre convocada pela organização Aldeias Infantis em parceria com o Alto Comissariado das Nações Unidas para Refugiados. Ao analisar as propostas submetidas por essa conferência livre constatouse que apesar da organização dedicar-se exclusivamente a defesa, garantia e promoção 
dos direitos de crianças e jovens apenas três ${ }^{15}$ das trinta e quatro propostas submetidas abordavam especificamente o tema.

Quanto às propostas aprovadas nas plenárias finais de ambas as conferências, estas foram classificadas com o intuito de observar como o tema da infância foi abordado nas conferências. Buscou-se identificar por meio da análise do conteúdo das propostas quantas delas consideravam a infância em seus textos. A partir dessa catalogação tornou-se viável comparar a entrada do tema nas duas edições da conferência, traçando paralelos e identificando diferenças entre elas.

Foram adotados os seguintes critérios para classificação: (i) foram descartadas aquelas que não se relacionavam diretamente com a infância e classificadas como "não" (não abordam expressamente a infância); (ii) foram classificadas como "sim" aquelas que abordam expressamente o tema; e (iii) foram classificadas como "específicas" aquelas que abordam exclusivamente o tema.

Uma vez que é plausível ponderar que grande parte das propostas aprovadas têm implicações sobre a infância, não se considerou as abordagens indiretas sobre o tópico no exercício dessa classificação de propostas. A ampliação da abrangência da classificação adotada tornaria pouco precisa a observação da forma como o tema foi trabalhado nas duas conferências. Assim, propostas como aquelas que demandavam orientação para regularização migratória ou a desburocratização de procedimentos administrativos foram classificadas como "não" (não abordam expressamente da infância) embora a regularização migratória tenha implicações diretas no acesso a direitos, inclusive da criança.

Os gráficos abaixo expressam a porcentagem de propostas conforme a classificação utilizada. Para a construção dos gráficos foi considerado como base o número de propostas aprovadas em cada edição (57 na primeira e 78 na segunda edição).

\footnotetext{
15 São elas: E2_CL7_09set_ZS_191 - Criar programas de assistência psicológica para crianças imigrantes que chegam na cidade. E6_CL7_09set_ZS_210 - Criar vagas em creches do município especificamente para crianças imigrantes. E7_CL7_09set_ZS_213 - Garantir vagas nas escolas públicas para crianças, adolescentes para que possam dar continuidade ao seus estudos e adultos e idosos para que possam terminar os seus estudos.
} 
Gráfico 1: Porcentagem de propostas classificadas considerando a infância como referência na $1^{a}$ Conferência Municipal de Políticas para Imigrantes (2013)

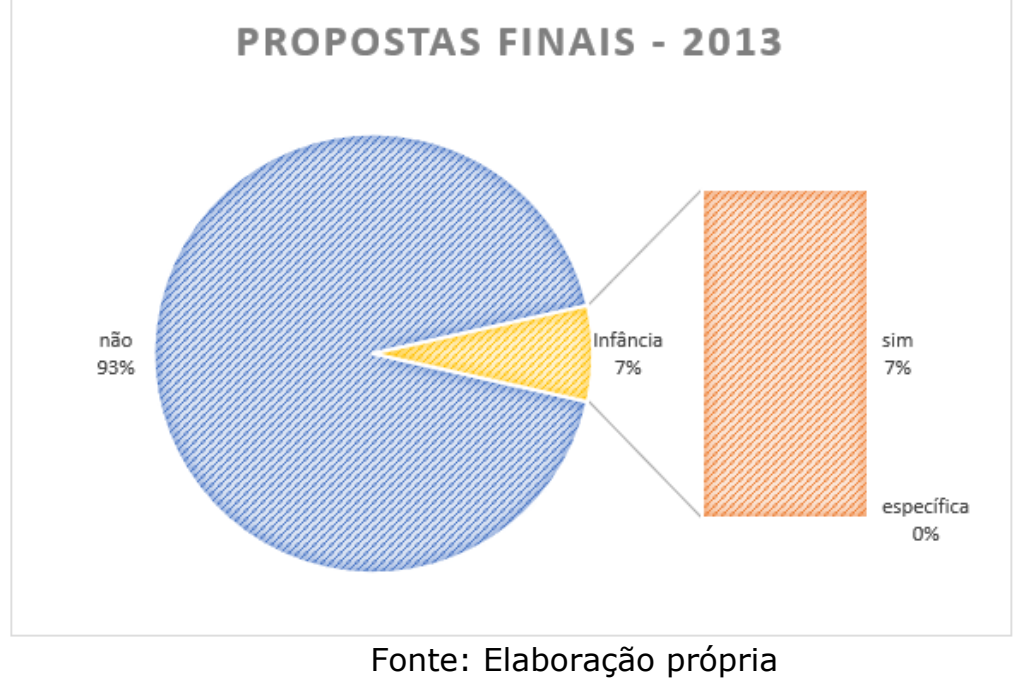

Gráfico 2: Porcentagem de propostas classificadas considerando a infância como referência na $2^{a}$ Conferência Municipal de Políticas para Imigrantes (2019)

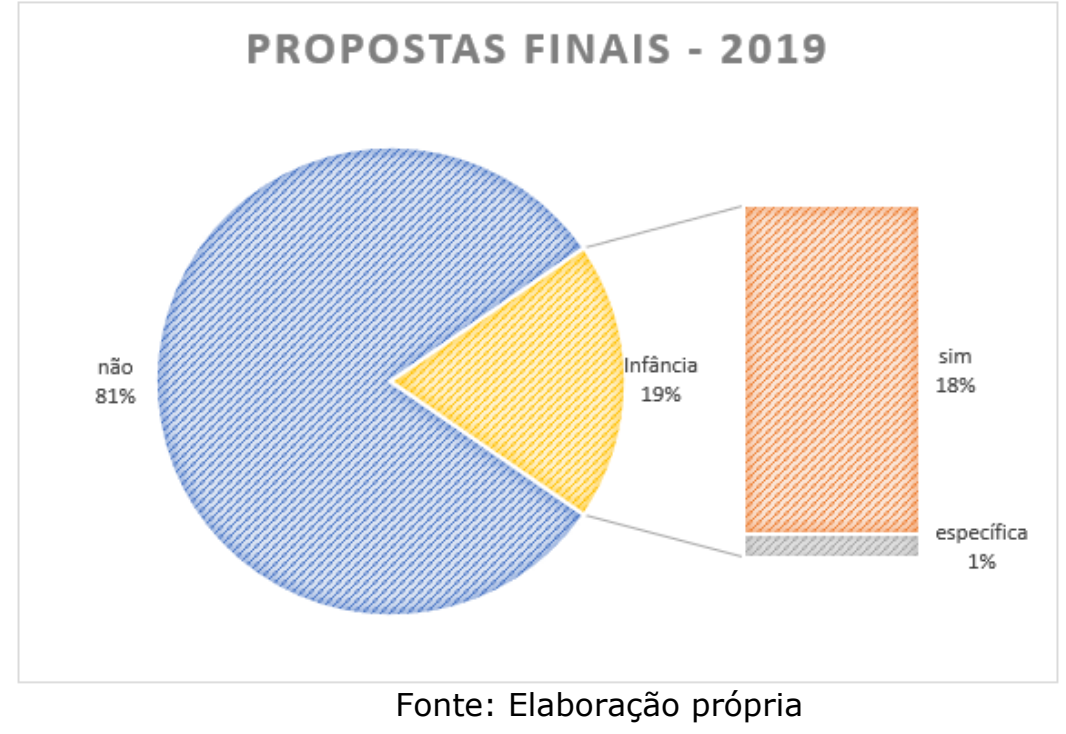

O exame dos gráficos permite extrair algumas considerações. Em ambos os anos a maioria das propostas, independentemente do eixo em que se encaixavam, não tratavam a temática da infância ( $93 \%$ e $81 \%$, respectivamente). No entanto, houve o crescimento do número de propostas que abordaram o tema (7\% para 19\%), sendo que a maior parte delas ocupou-se da infância conjuntamente com outros temas. É o caso, por exemplo, da proposta que versa sobre a melhoria e tipificação de Centros de Acolhida para Imigrantes (onde se incluiu o espaço dedicado à criança), ou de outra que trata da formação de servidores públicos sobre migração (incluindo conselheiros tutelares), ou ainda outra sobre a sensibilização de migrantes para a prevenção de violência contra mulher e população LGBTI+ (incluindo meninos migrantes). 
A respeito das propostas classificadas como "específicas" pode-se observar que apenas uma proposta (que corresponde a 1\%) dedicou-se exclusivamente à temática, não abordando a infância conjuntamente com outros temas. Esta proposta foi aprovada em 2019, no eixo V (mulheres e população LGBTI+: acesso a direitos e serviços), e demandou acesso amplo a creche e/ou criação de uma rede comunitária pública de cuidado de filhas/os.

É possível reconhecer, portanto, que as propostas se avolumaram de uma edição para outra, e dão indícios de se tornarem mais específicas, dedicando-se de forma cada vez mais direta à infância migrante. Nesse sentido, mostra-se necessário o acompanhamento relativo à manutenção dessa diretriz, ou a ruptura da mesma, nas próximas edições da Conferência Municipal de Políticas para Imigrantes.

Além do exame quantitativo das propostas, realizou-se também a análise dos seus conteúdos. O reconhecimento dos assuntos associados à infância foi feito por meio da identificação de palavras-chave nos conteúdos das propostas, não tendo necessariamente relação com os eixos temáticos nos quais se inseriram ${ }^{16}$. Os gráficos abaixo apresentam os assuntos abordados nas propostas aprovadas sobre a infância, conforme o ano de realização da conferência. Também para elaboração dos gráficos a seguir foi considerado como base o número de propostas aprovadas em cada edição (57 na primeira e 78 na segunda edição).

\footnotetext{
16 As duas edições da conferência tinham eixos temáticos distintos e, embora guardassem equivalências entre si, a associação de eixos não era imediata. Além disso, nem sempre a identificação de assuntos relacionados nos conteúdos das propostas tinha relação direta com o eixo temático em que estavam inseridas. Assim, ainda que uma proposta tenha sido aprovada no eixo temático III - valorização e incentivo à diversidade cultural de 2019, o conteúdo poderia estar relacionado com "educação", por exemplo.
} 
Gráfico 3: Assuntos abordados nas propostas aprovadas sobre infância na $1^{\text {a }}$ Conferência Municipal de Políticas para Imigrantes (2013)

INFÂNCIA E ASSUNTOS RELACIONADOS -

2013

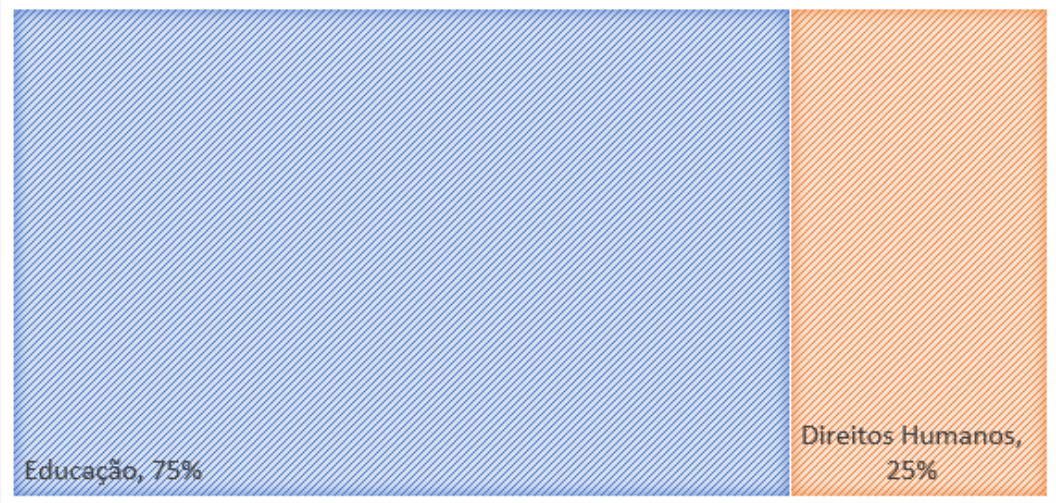

Fonte: Elaboração própria

Gráfico 4: Assuntos abordados nas propostas aprovadas sobre infância na $2^{a}$ Conferência Municipal de Políticas para Imigrantes (2019)

INFÂNCIA E ASSUNTOS RELACIONADOS -

2019

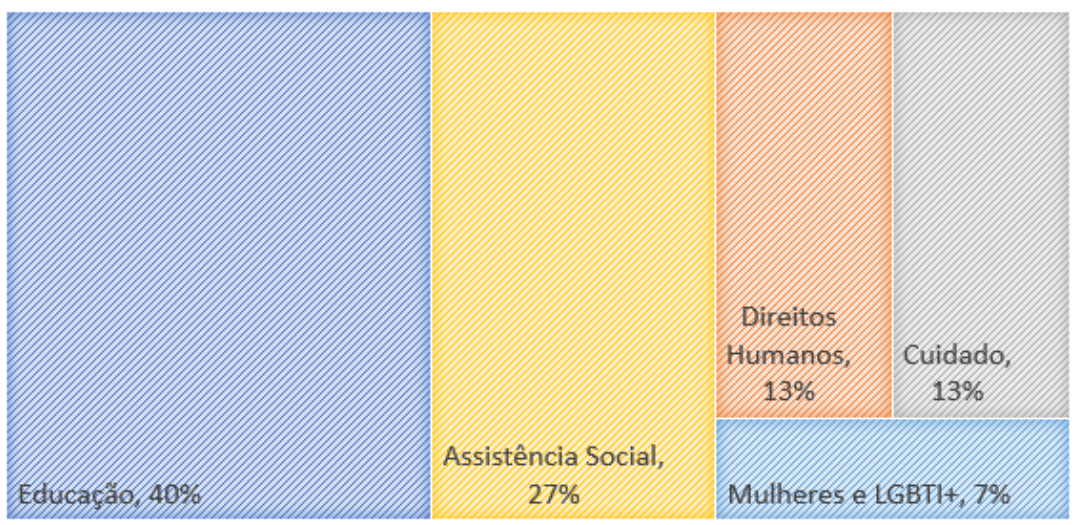

Fonte: Elaboração própria

Em 2013 apenas duas matérias foram envolvidas, sendo elas direitos humanos e educação, com maioria fazendo referência à educação (75\%). Em 2019, é possível notar a diversificação de assuntos correlacionados à infância (assistência social; cuidado; direitos humanos; assistência social; mulheres e LGBTI+), mantendo, no entanto, a predominância da intersecção infância/educação (40\%).

Assim, de um lado, verifica-se que a predominância das demandas aprovadas encontra-se na política educacional, embora proporcionalmente menor de um ano para o outro. Provavelmente, esse fato se deve à associação recorrente da infância com o direito à educação, afirmado na Constituição Federal brasileira como direito de todas as pessoas e dever do Estado e da família. De outro lado, nota-se que não foram contemplados os assuntos centrais de vários dos eixos temáticos das conferências, tais 
como saúde, cultura, habitação, participação social, esporte e lazer, e trabalho (incluindo, por exemplo, o combate ao trabalho infantil).

Algumas das propostas que expressamente trataram da infância o fizeram de forma secundária. Nesse campo se inserem as propostas identificadas como "cuidado". Estas incluíram a criança migrante como meio ou ponto de atenção visando à promoção de outro direito/serviço o qual a criança não era a beneficiária central. Por exemplo, uma das propostas discorre sobre a melhoria do Projeto Portas Abertas ${ }^{17}$ listando várias ações desejáveis, entre elas a necessidade de "apoio para os filhos". Ou seja, a atenção aos filhos nesse caso é uma das condições para a garantia de um direito (o aprendizado da Língua Portuguesa) de outros sujeitos (mães e pais ou responsáveis pelas crianças). O mesmo ocorre em outra proposta também identificada como "cuidado", que demanda a facilitação da participação da população migrante em encontros de participação social (reuniões, conferência etc.) a ser promovida inclusive por meio da criação de espaços de atenção às crianças filhas de participantes.

Entretanto, não foi identificada nenhuma proposta com objetivo de promover a participação efetiva e o protagonismo das crianças migrantes no espaço de participação social da conferência.

\section{NÚMERO DE CRIANÇAS E SUA FORMA DE PARTICIPAÇÃO}

Dois últimos pontos podem ser analisados no sentido de verificar a inserção da temática da infância nas conferências municipais: o número de crianças presentes nas conferências e a forma como foi pensada a sua presença/participação ao longo das mesmas. Tais pontos permitem identificar efetivamente como se deu a participação de crianças no evento de participação social observado.

No que diz respeito à primeira edição da Conferência Municipal de Políticas para Imigrantes, observou-se que não há registros etários dos participantes e tampouco foram encontrados indicativos sobre a presença de crianças nos dias da conferência ${ }^{18}$.

De modo que todos os dados aqui apresentados a seguir referem-se apenas à segunda edição da conferência.

\footnotetext{
17 Por meio do Projeto "Portas Abertas: Português para Imigrantes", o município oferta cursos de português gratuitos, contínuos e permanentes para pessoas migrantes na Rede de Municipal de Ensino. O Projeto é uma realização conjunta da Secretaria Municipal de Direitos Humanos e Cidadania e da Secretaria Municipal de Educação.

${ }_{18}$ A ausência do registro não significa necessariamente a ausência de crianças na primeira conferência, mas sim a falta de atenção no registro dessa especificidade.
} 
No que diz respeito ao número de participantes por faixa etária, de acordo com o Relatório Final da $2^{a}$ Conferência Municipal de Políticas para Imigrantes, apenas duas pessoas de 0 a 12 anos registraram-se como participantes da conferência. Tal número reflete somente a quantidade de pessoas cadastradas, não sendo possível precisar o número de crianças que estiveram presentes nos dias da conferência, mas que não se cadastraram como participantes ${ }^{19}$.

De toda forma, a participação de crianças na conferência vai além da análise quantitativa. É importante ponderar como a inclusão desse grupo foi pensada pela organização da conferência.

Cabe mencionar que nas discussões iniciais sobre a composição da Comissão Organizadora, particularmente sobre os representantes do governo municipal que deveriam ser incluídos, de acordo com a ata da $4^{a}$ Reunião do Grupo de Trabalho da Conferência Municipal para Política para Imigrantes (GT Conferência), registrou-se que o tema "criança e adolescente" deveria ganhar mais visibilidade e ser considerado de forma específica. Outras temáticas foram levantadas, nomeadamente pessoa idosa, população em situação de rua e juventude, que estavam em discussão naquele momento, e mulheres, LGBTI e igualdade racial, já previamente estabelecidos. A definição dos temas selecionados significaria a inclusão das áreas da Secretaria Municipal de Direitos Humanos e Cidadania relacionadas aos mesmos na referida Comissão. A decisão final foi por incluir a Coordenação de Direitos da Criança e Adolescente como membro da Comissão Organizadora20.

Relativamente à forma como se daria a participação de crianças na conferência, dois registros são importantes: a ata da 19a Reunião Ordinária do Conselho Municipal de Imigrantes, de junho de 2019, na qual se indicou a possibilidade de contar com o apoio de uma plataforma do Programa das Nações Unidas para o Desenvolvimento no cuidado de crianças. E, a ata da $4^{a}$ Reunião do GT Conferência, realizada em julho de 2019, em que se sugeriu a criação de um "grupo de cuidado para as crianças".

Durante os dias da conferência foi reservado um espaço físico para as crianças migrantes presentes, com atividades lúdicas e sob os cuidados de voluntários. Além disso, a Coordenação também considerou como parte da estratégia de atenção à criança migrante durante a realização da conferência a seleção de espaço adequado e a disponibilização de alimentação no decorrer das atividades.

\footnotetext{
${ }^{19}$ As autoras desse artigo estiveram presentes durante todo o processo de realização da segunda edição e puderam observar a presença tímida e pouco numerosa de crianças.

20 Resolução N 03/CMI/2019.
} 
Embora tenha havido a preocupação em atender a demanda pelo ato de cuidar das crianças, observa-se que a organização da conferência não se ateve em incluir a criança migrante como sujeito protagonista de suas próprias demandas. A atenção recaiu, portanto, na garantia da participação de mulheres e homens com filhas e filhos, reforçando a ideia apresentada na introdução do texto do olhar para a criança enquanto parte de um binômio aparentemente indissociável com suas mães, seus pais ou responsáveis legais (cf. CLACSO, 2020).

Nesse sentido, cabe enfatizar a importância da escuta e consideração do ponto de vista da criança migrante, levando em conta sua idade, seu nível de maturidade e as metodologias mais adequadas de garantir sua participação plena. As crianças também têm o direito de expressarem suas opiniões diante de decisões que lhe dizem respeito e que trazem impactos diretos na sua vida cotidiana (KOZICA; VAN ELK, 2020). Suas experiências, impressões e considerações têm muito a enriquecer o debate sobre a construção de políticas cujas crianças são as principais destinatárias.

Verifica-se que outras iniciativas de participação social apresentam possibilidades de metodologias de participação de crianças nesses espaços como, por exemplo, a IX Conferência Lúdica Municipal dos Direitos Humanos de Crianças e Adolescentes do Município de São Paulo do ano de 2018, que contou com 143 participantes (22 crianças e 118 adolescentes), moradores de 28 Subprefeituras do município. Dela resultaram 43 propostas, elaboradas a partir de metodologias que respeitaram as diferentes linguagens e que separaram para cada eixo temático, um grupo de crianças e um de adolescentes (Cf. SMDHC; CEAPG, 2018).

Assim, a promoção da participação e da agência de crianças nesses espaços reflete a necessidade de superar uma perspectiva essencialmente centrada na pessoa adulta nos espaços de participação social, trazendo ao centro das preocupações a subjetividade migrante. Admitir as crianças migrantes como pessoas com vontades, experiências e subjetividades próprias implicaria no reconhecimento de um universo cognitivo diferente do universo adulto (Cf. PAVEZ, 2012; MOSCOSO, 2013 apud. CLACSO, 2020) e consequentemente na realização de um grande potencial de contribuição desse grupo em processos de discussão de priorização de demandas.

\section{CONSIDERAÇÕES FINAIS}

Ao longo do artigo foram apresentadas reflexões sobre o tema da infância migrante a partir do contexto da cidade de São Paulo e especificamente da realização 
de duas Conferências Municipais de Políticas para Imigrantes realizadas nos anos de 2013 e 2019.

Constatou-se que nenhuma das duas edições dedicou um eixo específico para o tema da infância, mas a segunda conferência trazia a menção à especificidade da criança migrante em um dos quatro temas transversais a serem observados e, por sugestão da própria Comissão Organizadora, houve o indicativo de que para a próxima conferência, a ser realizada em 2021, seja considerada a possibilidade de inclusão de um eixo específico com o tema das crianças e adolescentes migrantes.

Sobre as propostas, apesar da referência ainda tímida à questão da infância migrante, verificou-se que estas se avolumaram, se apresentaram de forma cada vez mais direta e diversificaram os assuntos correlacionados de uma edição para outra.

Relativamente aos registros etários dos participantes, identificou-se que não foram colhidos estes dados e que não há registro da presença de crianças na primeira edição da conferência. Na segunda edição o número de crianças presentes era pouco significativo. A preocupação com a sua participação nessa ocasião foi especialmente voltada ao cuidado, com atividades lúdicas não necessariamente vinculadas ao lema da conferência: "Somos Tod@s Cidadãos".

Para a realização da próxima Conferência Municipal de Políticas para Imigrantes caberá a Comissão Organizadora decidir pela priorização ou não do reconhecimento das especificidades da criança e do adolescente dentro da população migrante como um eixo temático específico, conforme sugeriu a avaliação da Comissão Organizadora da atual conferência. O reconhecimento de temáticas específicas já ocorreu anteriormente, como no caso de mulheres e LGBTI+, e pode ser notado na ampliação de eixos temáticos que refletem demandas sociais emergentes.

Além disso, tocará aos organizadores refletir sobre a possível adoção de novas metodologias a fim de ampliar a participação desse público específico de forma ativa, conferindo-Ihe agência sobre suas próprias demandas e permitindo acolher suas contribuições.

Como indicado no início deste artigo, a infância é uma pauta cada vez mais presente no cenário migratório nacional e também local. Nesse sentido, o desenvolvimento da atenção ao público infantil poderá indicar um caminho a ser trilhado com intuito de promover a inclusão de crianças na formulação de políticas públicas às quais são as principais destinatárias. 


\section{REFERÊNCIAS}

BAUMGARTNER, Frank R.; JONES, Bryan D. Agendas and instability in American politics. University of Chicago Press, 2a edição, 2009 [1993].

BREITENVIESER, Camila Barrero. Políticas para Migrantes: formação da agenda do governo municipal de São Paulo. 2019. 207f. Dissertação (Mestrado em Administração Pública e Governo). Escola de Administração de Empresas de São Paulo. Fundação Getúlio Vargas (FGV), 2019.

CLACSO (Consejo Latinoamericano de Ciencias Sociales). Voces y experiencias de la niñez y adolescencia venezolana migrante en Brasil, Colombia, Ecuador y Perú. Ciudad Autónoma de Buenos Aires: CLACSO, 2020.

CONFERÊNCIA JUDICIAL IBERO-AMERICANA. Regras de Brasília Sobre Acesso à Justiça das Pessoas em Condição de Vulnerabilidade. Brasília, 2008.

IPPDH (Instituto de Políticas Públicas en Derechos Humanos del Mercosur). Iniciativa Regional Foco Niñez Migrante. Buenos Aires, 2019.

IPPDH (Instituto de Políticas Públicas en Derechos Humanos del Mercosur). Parecer Consultivo sobre as crianças migrantes OC-21. 15 dez. 2015. Disponível em: <https://www.ippdh.mercosur.int/pt-br/parecer-consultivo-sobre-as-criancasmigrantes-oc-21/>. Acesso em: 21 abr. 2020.

KOZICA, Irene; VAN ELK, Patricia. Manual de escuta de crianças e adolescentes migrantes. Centro Internacional para o Desenvolvimento das Políticas Migratórias (ICMPD), 2020.

OIM (Organização Internacional para as Migrações - Brasil). Protocolo de assistência a migrantes em situação de vulnerabilidade. Brasília, 2018.

ONU (Organização das Nações Unidas - Divisão de População do Departamento de Economia e Assuntos Sociais). Inventário de Migração Internacional. 2019.

Disponível em:

<https://www.un.org/en/development/desa/population/migration/data/estimates2/es timates19.asp>. Acesso em: 19 set. 2019.

SAMPAIO, Cyntia; BARALDI, Camila. Políticas migratórias em nível local: análise sobre a institucionalização da política municipal para a população imigrante de São Paulo. CEPAL - Documentos de Projetos. Disponível em <http://hdl.handle.net/11362/44491>. Acesso em: 24 jan. 2019.

SMDHC; CEAPG (Secretaria Municipal de Direitos Humanos e Cidadania; Centro de Estudos em Administração Pública e Governo). IX Conferência Lúdica Municipal dos Direitos Humanos de Crianças e Adolescentes do Município de São Paulo, São Paulo, 2018. Disponível em:

https://www.prefeitura.sp.gov.br/cidade/secretarias/upload/direitos_humanos/CMDCA /CONFERENCIA/Resultados\%20IX\%20ludica.pdf. Acesso em 12 dez.2019. 
SMDHC (Secretaria Municipal de Direitos Humanos e Cidadania de São Paulo). Relatório Final da $2^{a}$ Conferência Municipal de Políticas para Imigrantes (2019). São Paulo, no prelo.

SMDHC (Secretaria Municipal de Direitos Humanos e Cidadania de São Paulo). Caderno da Conferência (2019) - $2^{a}$ Conferência Municipal de Políticas para Imgirantes. São Paulo, 2019a. Disponível em:

https://www.prefeitura.sp.gov.br/cidade/secretarias/upload/direitos_humanos/partici pacao_social/CONSELHOS/CONSELHO\%20IMIGRANTES/CONFERENCIA/Caderno\%20C onf.pdf. Acesso em: 12 dez. 2019.

SMDHC (Secretaria Municipal de Direitos Humanos e Cidadania de São Paulo). Propostas Aprovadas na Plenária Final da Conferência - $2^{a}$ Conferência Municipal de Políticas para Imgirantes. São Paulo, 2019b. Disponível em:

https://www.prefeitura.sp.gov.br/cidade/secretarias/upload/direitos_humanos/partici pacao_social/CONSELHOS/CONSELHO\%20IMIGRANTES/CONFERENCIA/ATUALIZADO3 0-10/Propostas\%20finais.pdf .Acesso em: 12 dez. 2019.

SMDHC (Secretaria Municipal de Direitos Humanos e Cidadania de São Paulo).

Documento de Metodologia - 2a Conferência Municipal de Políticas para Imgirantes. São Paulo, 2019c. Disponível em:

https://www.prefeitura.sp.gov.br/cidade/secretarias/upload/direitos_humanos/partici pacao_social/CONSELHOS/CONSELHO\%20IMIGRANTES/CONFERENCIA/ATUALIZADO3 0-10/Documento_de_Metodologia-convertido.pdf Acesso em: 12 dez. 2019.

SMDHC (Secretaria Municipal de Direitos Humanos e Cidadania de São Paulo).

Documento de Codificação de Propostas - $2^{a}$ Conferência Municipal de Políticas para Imgirantes. São Paulo, 2019d. Disponível em:

https://www.prefeitura.sp.gov.br/cidade/secretarias/upload/direitos_humanos/partici pacao_social/CONSELHOS/CONSELHO\%20IMIGRANTES/CONFERENCIA/ATUALIZADO3 0-10/Codificacao\%20Propostas-correto.pdf. Acesso em: 12 dez. 2019.

SMDHC (Secretaria Municipal de Direitos Humanos e Cidadania de São Paulo). Atas das Reuniões da Comissão Organizadora - $2^{a}$ Conferência Municipal de Políticas para Imgirantes. São Paulo, 2019e. Disponível em:

https://www.prefeitura.sp.gov.br/cidade/secretarias/direitos_humanos/imigrantes_e_ trabalho_decente/conferencia_imigrantes/index.php?p=281124. Acesso em: 02 abr. 2020.

SMDHC (Secretaria Municipal de Direitos Humanos e Cidadania de São Paulo). Atas das Reuniões do Conselho Municipal de Imigrantes - 2019. São Paulo, 2019 f. Disponível em:

https://www.prefeitura.sp.gov.br/cidade/secretarias/direitos_humanos/imigrantes_e_ trabalho_decente/conselho_municipal_de_imigrantes/index.php?p=279128. Acesso em: 02 abr. 2020.

SMDHC (Secretaria Municipal de Direitos Humanos e Cidadania de São Paulo). Atas das Reuniões do GT Conferência - 2019. São Paulo, 2019g. Disponível em:

https://www.prefeitura.sp.gov.br/cidade/secretarias/direitos_humanos/participacao_s ocial/conselhos_e_orgaos_colegiados/gcmi/index.php?p=280527. Acesso em: 02 abr. 2020. 
SMDHC (Secretaria Municipal de Direitos Humanos e Cidadania de São Paulo).

Documento Final da $1^{a}$ Conferência Municipal de Políticas para Imigrantes (2013). São Paulo, 2013. Disponível em:

https://www.prefeitura.sp.gov.br/cidade/secretarias/upload/direitos_humanos/Doc\%2

OFinal_Conf\%20Mun\%20Imigrantes\%20de\%20SP_2014.pdf. Acesso em 12 dez.2019.

UNDOC (Escritório das Nações Unidas sobre Drogas e Crime). Relatório Global sobre Tráfico de Pessoas, 2018.

UNHCR (United Nations High Commissioner for Refugees). Global Trends: Forced Displacement in 2018. Genebra, Switzerland. 2019.

UNICEF (Fundo das Nações Unidas para a Infância). Dados coletados em abril de 2020 e disponíveis em: <https://www.unicef.org/children-uprooted>. Acesso em: 14 abr. 2020.

UNICEF. Migration flows in Latin America and the Caribbean. Situation Report no 3, 2019.

VENTURA, Deisy; GUIMARÃES, Feliciano de Sá; REIS, Rossana Rocha (coord.).

Imigrantes em São Paulo: diagnóstico do atendimento à população imigrante no município e perfil dos imigrantes usuários de serviços públicos, E-book disponível em doi.org/10.11606/9788569229018, 2017

\section{NOTAS}

CAMINHOS DA PARTICIPAÇÃO SOCIAL NA FORMULAÇÃO DE POLÍTICAS PÚBLICAS: INFÂNCIA E MIGRAÇÃO INTERNACIONAL EM SÃO PAULO

Social participation pathways on the formulation of public policies: childhood and international migration in São Paulo

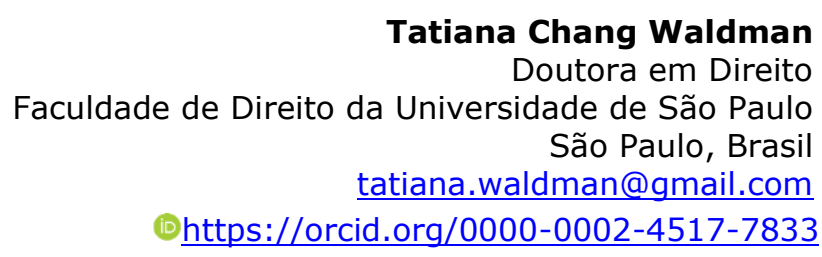

Camila Barrero Breitenvieser Mestre em Administração Pública e Governo Fundação Getúlio Vargas (FGV-EAESP)

São Paulo, Brasil camilabreitenvieser@gmail.com (1) https://orcid.org/0000-0002-0983-404X

Endereço de correspondência do principal autor

Escola do Parlamento - Viaduto Jacareí, no100 - 130 andar - sala 1302-A.

\section{AGRADECIMENTOS}

Agradecemos à Coordenação de Políticas para Imigrantes e Promoção do Trabalho Decente (CPMigTD) pela oportunidade de participar e contribuir diretamente em todas as etapas da $2^{a}$ Conferência Municipal de Políticas para Imigrantes, proporcionando subsídios e reflexões para a elaboração deste artigo. 


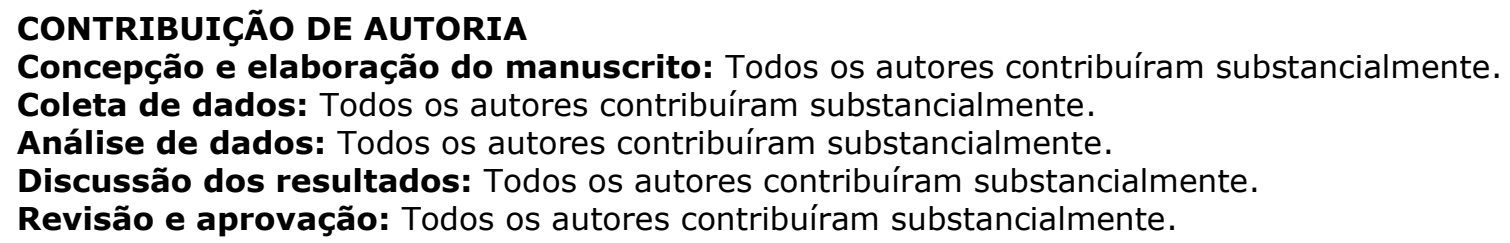

\section{FINANCIAMENTO}

Não se aplica.

\section{CONSENTIMENTO DE USO DE IMAGEM}

Não se aplica.

\section{APROVAÇÃO DE COMITÊ DE ÉTICA EM PESQUISA \\ Não se aplica.}

\section{CONFLITO DE INTERESSES}

Não se aplica.

LICENÇA DE USO - uso exclusivo da revista

Os autores cedem à Zero-a-Seis os direitos exclusivos de primeira publicação, com o trabalho simultaneamente licenciado sob a Licença Creative Commons Attribution (CC BY) 4.0 International. Esta licença permite que terceiros remixem, adaptem e criem a partir do trabalho publicado, atribuindo o devido crédito de autoria e publicação inicial neste periódico. Os autores têm autorização para assumir contratos adicionais separadamente, para distribuição não exclusiva da versão do trabalho publicada neste periódico (ex.: publicar em repositório institucional, em site pessoal, publicar uma tradução, ou como capítulo de livro), com reconhecimento de autoria e publicação inicial neste periódico.

PUBLISHER - uso exclusivo da revista

Universidade Federal de Santa Catarina. Núcleo de Estudos e Pesquisas da Educação na Pequena Infância - NUPEIN/CED/UFSC. Publicação no Portal de Periódicos UFSC. As ideias expressadas neste artigo são de responsabilidade de seus autores, não representando, necessariamente, a opinião dos editores ou da universidade.

EDITORES - uso exclusivo da revista Márcia Buss-Simão e Kátia Agostinho.

HISTÓRICO - uso exclusivo da revista

Recebido em: 30-04-2020 - Aprovado em: 03-06-2020 